\title{
É SEMPRE BOM SER NOVAMENTE RECONHECIDO
}

Maria Haddock Lobo*

\begin{abstract}
Resumo
Após a viralização nas redes sociais de seu depoimento ao prefeito de São Paulo, um dependente químico em situação de rua e líder na Cracolândia de SP é reconhecido por ex-colegas, como esta que aqui escreve. Neste relato, tento capturar sua identidade e significados que ele constrói em seu discurso. Retomo assim minha interação com meu amigo em um mosaico que inclui fragmentos de sua fala, cacos de minha memória e achados de pesquisa, mapeando rotas narrativas no ambiente online e além deste.
\end{abstract}

\section{Palavras-chave}

Cracolândia. Autoetnografia. Redução de Danos. Redes Sociais.

\section{1) Ligando pontos de uma história num outro espaço-tempo}

A maior dificuldade em contar esta história tem sido, com recorrência, escolher de onde pegá-la, de onde laçá-la, pois não há começo, meio ou fim; há em lugar disso uma incessante circulação em espiral com algumas epifanias entre uma volta e outra, algo que se pode experimentar também em estados alterados de consciência.

Assim, o que virá a seguir é um olhar por uma fresta, um acontecimento rápido, a biografia de um sujeito e a (auto) biografia de um encontro, a música Sinal Fechado ${ }^{1}$, um verbete incompleto, fora de ordem; são gambiarras da minha memória, é catação de cacos. E como nos clicares e rolares de tela de nossos tempos, é tudo muito interrompido.

\section{2) Nomes e vidas}

Nos primeiros anos de escola ele foi o Sarda, apelido mais do que óbvio para crianças ruivas e de pele pintada. Para a família sempre foi Cadu; nos documentos, Carlos

\footnotetext{
* Jornalista de formação, atualmente cursa Mestrado em Estudos da Linguagem Na PUC-Rio, com foco na abordagem social; em arte desenvolve pesquisa sobre cadernos e memória pessoal.

${ }^{1}$ Composição de Chico Buarque:

Olá, como vai/ Eu vou indo e você tudo bem/Tudo bem eu vou indo/ Correndo pegar meu lugar No futuro e você/ Tudo bem eu vou indo/ Em busca de um sono tranquilo/ Quem Sabe/ Quanto tempo, pois é quanto tempo/ Me perdoe a pressa/É a alma dos nossos negócios/ Qual, não tem de quê/ Eu também só ando a cem/ Quando é que você telefona/ Precisamos nos ver por aí/ Pra semana prometo talvez nos vejamos/ Quem sabe/ Quanto tempo pois é/ Quanto tempo/ Tanta coisa que eu tinha a dizer/ Mas eu sumi na poeira das ruas/ Eu também tenho algo a dizer/ Mas me foge à lembrança/ Por favor telefone eu preciso saber/ Alguma coisa rapidamente/ Pra semana, o sinal/ Eu procuro você, vai abrir, vai abrir/ Eu prometo não esqueço/ For favor não esqueça, não esqueça/ Não esqueça/ Adeus
} 
Eduardo. Na adolescência, aquele cara de cabelos ruivos e longos logo virou Jesus. Na Cracolândia, provavelmente por sua cara de gringo, ficou sendo o Alemão. Para o prefeito, era Lixo Humano, e ao viralizar em nossas telas falando justamente sobre isso, volta ao Sarda da infância, num movimento circular de nomes e vidas vividas.

Este sujeito de muitos apelidos é antes um amigo de muito tempo, daqueles que os descaminhos da vida afastam, mas que novidades tecnológicas em breve prometeriam reconectar com uma facilidade aparentemente incrível, ao toque de nomes em caixas de busca. Mas não foi assim que nos reencontramos. Nenhum de seus nomes estava nas “redes sociais". Para nós, ex-colegas de escola, ele não estava mais em lugar nenhum, ele não existia. Não até aquela semana de maio de 2017.

Anos antes, enquanto tecíamos encontros e reencontros e começávamos a atar nossos nós na grande novidade da "rede social", este sujeito acentuava seu movimento de apartar-se, de viver nas ruas, de viver "no fluxo"3 e nos não-lugares. Usuário de drogas pesadas e de orelhões, mantinha contato semanal com a família, que já não contava mais com nenhuma promessa de "cura" e, de uma forma que pode parecer torta para muitos, o supria com uma pequena quantia semanal, como forma de afastá-lo de atividades criminosas.

Assim, numa noite, já há mais de dez anos vivendo na Cracolândia, ele tomou mais uma dose, pegou fôlego, elaborou ali na hora e, acocorado diante de uma câmera, falou, falou, falou montes. Nove minutos de uma falação cantada, seu recado agridoce para o prefeito, o "Sr. Perfeito", que em campanha havia se referido aos moradores e frequentadores daquele território como "lixo vivo"4. Em dado momento, ele simula uma troca de lugar com seu interlocutor, e sugere a este que faça um mea culpa, abre aspas:

Não há problema nenhum em dizer "pô exagerei aí!" Chamei um monte de gente de lixo humano e mal sei eu que tem cara ali que é formado em universidade, que tem outro que já foi um policial militar, que tem outro que de repente estudou no mesmo colégio que eu, que a maioria tem mãe, filho, irmão, que num nasceu de chocadeira.

\footnotetext{
${ }^{2}$ Lançado em 2004, o Facebook chega oficialmente ao Brasil em 2007.

${ }^{3}$ Chama-se fluxo tanto a concentração de usuários do crack quanto a movimentação dos mesmos, em grupos.

4 "A cidade é um lixo vivo, parece um filme escabroso. Hoje, a cidade tem 16 mil moradores de rua, no início dessa gestão eram 6 mil. Antes tinha uma Cracolândia na cidade com 400 usuários e hoje são três mil espalhados por seis cracolândias." Fonte:

https://blogdosakamoto.blogosfera.uol.com.br/2016/12/05/caro-joao-doria-precisamos-mesmo-limpar-spde-todo-tipo-de-preconceito/ último acesso em 18/06/2019
} 


\section{3) A Craco resiste e viraliza}

Este vídeo ${ }^{5}$ foi publicado por um coletivo de Direitos Humanos no início de 2017, logo após a posse do prefeito João Dória Jr. Por alguma razão algorítmica, em maio do mesmo ano aquela fala "viralizava", alcançando mais de um milhão de visualizações e gerando milhares de comentários em fóruns de discussão em páginas do Facebook e em publicações da mídia hegemônica presente no ambiente online. Naqueles dias a Cracolândia, um território de fronteiras humanas e flutuantes - o fluxo -, vinha passando por mais episódios de extrema violência policial e desrespeito aos direitos humanos, com lançamento de bombas e prédios sendo derrubados com pessoas dentro. A megaoperação ${ }^{6}$ era uma promessa de campanha: "limpar" a cobiçada região da Luz, no centro de São Paulo, dos usuários de drogas e moradores de rua.

Por cerca de dez dias fomos servidos de pautas sobre adição, política nacional de drogas, filosofia de redução de danos, internação compulsória, proibicionismo, antiproibicionismo, guerra ao tráfico, histórias-dramáticas-de-jovens-bem-nascidos-dazona-sul-carioca-que-se-perdem-no-mundo-das-drogas etc. Mas não se falou muito sobre, afinal, de onde surgiu aquela gravação, quais as motivações por trás daquele evento disparador.

\section{4) Reduzir danos}

O recado passa também a chamar muita atenção para uma certa página - o coletivo de redutores de riscos e danos chamado A Craco Resiste, canal onde o vídeo foi publicado originalmente. A Política/ Filosofia da Redução de Riscos e Danos (RRD) considera os saberes dos usuários de drogas como legítimos e rejeita como único paradigma de tratamento o paradigma da abstinência. As primeiras destas experiências surgem na Holanda, na década de 1980, como forma de conter o avanço de epidemias virais e do HIV, com o programa de troca de seringas para uso de drogas injetáveis. São lutas correlatas a esta causa, o antiproibicionismo com relação às drogas e a luta

5 O vídeo, publicado em janeiro de 2017 pelo coletivo A Craco Resiste, https://www.facebook.com/ACracoResiste/ foi replicado em maio do mesmo ano pela página Jornalistas Livres https://www.facebook.com/jornalistaslivres/videos/462914107165805/ (último acesso em 24/04/2019).

6 https://www1.folha.uol.com.br/cotidiano/2017/05/1886022-policia-faz-megaoperacao-de-combate-aotrafico-na-cracolandia.shtml (último acesso em 23/06/2019). 
antimanicomial. Na página de A Craco Resiste, em sua seção "Dúvidas mais frequentes", assim está resumida:

As estratégias (da RRD) são múltiplas, vão desde a distribuição de insumos, como cachimbos e seringas, evitando ferimentos e contaminação por doenças contagiosas, até ações que garantam moradia e possibilidade de renda aos usuários. Também é uma faceta importante o diálogo direto com os envolvidos, para propor medidas adaptadas à realidade de cada um e convidar o próprio indivíduo a pensar estratégias de cuidado para si mesmo (junho de 2017).

Este coletivo autônomo surge assim em dezembro de 2016 como forma de resistência à violência policial diante das ameaças do então recém-eleito prefeito de São Paulo, João Dória Jr., que em campanha havia prometido "limpar a Cracolândia". Em 15 de janeiro de 2017 os ativistas da Craco publicam um manifesto em sua página, que conta hoje com quase 18 mil seguidores:

Estamos aqui para resistir às políticas que pretendem tratar a população de rua e os usuários de drogas como lixo a ser varrido das ruas. Não vamos aceitar a desarticulação dos serviços de atendimento ou qualquer tipo de agressão [...] acreditamos no cuidado e nos laços de afeto como forma de fortalecimento individual e comunitário (janeiro de 2017).

Durante as vigílias culturais promovidas pelo coletivo, os usuários de drogas e pessoas em situação de rua têm acesso a espetáculos de música, oficinas de escrita e rodas de conversa, entre outras atividades. Mas a ideia de um movimento com este nome soou paradoxal e absurda, provocadora aos que não praticam o dificílimo exercício do desapego de essencializações simplistas, da experiência da empatia não seletiva. Resistir a quê? A que podem resistir estes que não têm nada a perder? Gritavam forte naquele discurso as fricções, os atritos mobilizadores, os impasses, desconfortos e paradoxos de quem resiste pelo direito de existir. Nos discursos conservadores imperava o tom de deboche. Mas, o prefeito de São Paulo deu-se ao trabalho de responder ${ }^{7}$.

\section{5) O nosso reencontro}

\footnotetext{
${ }^{7}$ https://www.facebook.com/jdoriajr/videos/cracol\%C3\%A2ndia/1464034203653386/ (último acesso em 24/04/2019)
} 
Algumas das milhares de visualizações deste depoimento ao prefeito aconteceram de minha casa, de "meu IP", quando trombei com a imagem deste senhor barbudo, ruivo, de boné. Não era uma fotografia, era imagem em movimento, e quando apertei o triângulo preto que indica "tocar", assisti absolutamente estatelada aos nove minutos daquela voz e prosódias inconfundíveis do amigo que fazia doze anos eu tinha visto pela última vez. Eu havia retomado meus estudos após vinte anos de formada e justo naquela semana estávamos estudando Análise do Discurso. Aquilo não parecia acaso.

Para nós, ele era o Jesus, apelido dado ao cara articulado, ruivo e de cabelos compridos que chegou no primeiro ano do nosso Ensino Médio, saído de uma escola muito tradicional, o que não era bem o caso da nossa, e com quem fumamos muita maconha, fizemos muitas festas e ouvimos muito rock'n'roll, quase sempre com ele ao violão. O uso problemático de drogas ilícitas se acentuou nele nesta passagem para a vida adulta, justo quando nos dividíamos e seguíamos para nossos cursos universitários. Ainda não havia a Internet tal qual a conhecemos hoje, e os descaminhos foram rápidos em nos afastar. Mas agora ele estava ali, ao centro da minha tela de moldura azul real, aparente eixo de conexão com tudo e com todos, "a rede social". Em questão de segundos identifiquei a fonte primária da publicação, abri uma caixa de diálogo de mensagens instantâneas no canto direito inferior da tela, cujo ícone é um raio, e me apresentei (sem medo, mas não sem alguma estranheza, admito, afinal eu escrevia para uma página de nome A Craco Resiste; quem me responderia, um "cracudo"?).

Mandei dizer que nós, seus amigos de escola, estávamos orgulhosos dele - e ele saberia de quem eu estava falando. Dois dias depois um ativista do coletivo me respondeu, transmitindo um recado seu, um áudio em arquivo MP3. Ele pigarreia, e ao fundo um jazz come solto:

"[...] é realmente muito legal vocês se dirigirem a mim ainda como amigos da escola, né? e neste descaminho que é a vida, né? o bom é ver que por maior que seja essa distância e tempo, por mais que eles digam não, é sempre bom a gente conseguir ser novamente reconhecido, né?"

Do lado de lá de outras telas, nosso adolescente Jesus era reconhecido por outras turmas como o menino Sarda. As dimensões de sua importância são frestas, e estas se multiplicavam exponencialmente. Nós, os amigos de adolescência, da escola-cursinho, estávamos lentos, estatelados, chapados diante daquilo, pensando em como acessá-lo, ele que em seu "discurso" admitia e mesmo defendia, com todas as letras, aquela sua forma 
de vida. A nós, ele pareceu muito lúcido. Seus amigos de infância na certa viam na tela um outro sujeito, o Sarda, criança indefesa, o menino ruivo e sardento inevitavelmente apelidado, fragilidade em pessoa que deveria ser resgatada e salva o mais rápido possível. Uma vaquinha virtual ${ }^{8}$, que aliás nunca saiu do ar, foi lançada por estes outros amigos para levantar fundos destinados à internação e tratamento, e "o resgate" começou a ser organizado, em tempo real, com uma publicação aberta ${ }^{9}$ onde todos lamentavam, enalteciam, comentavam e sugeriam. Esta publicação, que tem 172 comentários e 275 compartilhamentos está disponível ainda hoje, mas flutua parada no tempo. É, até o presente momento em que escrevo, uma "postagem-pompéia", que desde o dia 11 de junho de 2017 não recebe comentários.

A dimensão de sua importância são frestas. E uma história destas, com um personagem aparentemente "tão fora de seu lugar", não passaria desapercebida pela mídia hegemônica, que, num ritmo "de produção", enviou ao território da Cracolândia seus repórteres, na caçada ao Alemão do fluxo, ao Sarda do primário, ao Jesus do prévestibular, ao Cadu de sua família.

\section{6) A saída}

Naqueles dias eu passei a acompanhar compulsivamente esta publicação aberta no Facebook em que se organizava o resgate, mas o ritmo de atualizações já não era o mesmo o que me levava a imaginar que o grupo havia mudado para alguma outra plataforma de acesso mais reservado, provavelmente um grupo de Whatsapp ${ }^{10}$. No entanto, através da ferramenta "Amigos em Comum" duas pessoas tornaram-se meus "informantes", a quem chamarei O Primo e A Vizinha. Foram eles que me comunicaram, quando finalmente localizaram o Cadu, que ele havia concordado em se internar numa clínica, "mas que tinha que ser aquela, e somente aquela", ele teria exigido.

E assim ele passou uma fronteira; uma não, muitas. Saiu de lá vivo para contar a história. E saiu contando em trânsito, em fluxo físico e midiático, acontecendo-se e transmitindo-se, na velocidade da luz. Soube por estes amigos em comum que no

\footnotetext{
${ }^{8}$ https://www.kickante.com.br/campanhas/nova-chance-ao-cadu (último acesso em 24/04/2019)

${ }^{9}$ https://www.facebook.com/chmjr/posts/10210725201498825? tn =K-R (último acesso em 24/04/2019)

${ }^{10}$ Aplicativo de mensagens instantâneas por celular que suporta texto, imagens e vídeos. Lançado em 2009, é considerado atualmente a maior rede de troca de mensagens do mundo, com 1.5 bilhões de usuários.
} 
conturbado trajeto de ambulância de São Paulo à serra do Rio de Janeiro, ele falou de livros, fez uma longa lista para que lhe fossem enviados, exibiu uma memória e cognição intactas, contando a história de todos os seus companheiros do fluxo, com nomes e sobrenomes, fez algumas exigências de pop star e, voluntariamente, pela última vez, internou-se. Depois ficou tudo escuro. Em questão de dias deu-se o resgate, deu-se a cobertura jornalística, deu-se a internação, deu-se a morte.

Exatos dez dias após eu ter recebido aquele recado em áudio no canto direito inferior de minha tela, preciso sair mais cedo de minha aula de "Linguagem e Sociedade", e estou dentro de um táxi, rumo ao cemitério do Caju. Doze anos desde nosso último encontro corpóreo, num consultório médico em Ipanema, quando, depois do susto do “você por aqui?!" e de um abraço apertado, ele me entregou um papelzinho com alguns números de telefone, para os quais eu nunca disquei e uma frase, ao lado de um endereço "www". A frase dizia: "ver as obras" e se referia ao trabalho de sua ex-mulher, artista plástica, de quem, pelas minhas contas hoje, ele estava recém-separado.

Olho para o meu amigo, ele tem a minha idade, mas quando morre é meu bisavô em seu caixão. Habitou um corpo autodeclarado doente pela maior parte de seus anos cronológicos. Foi escolha própria aplicar-se e consumir substâncias que lhe garantiram uma vida de consciência alterada pela maior parte do tempo, se possível.

Ao decidir sair da Cracolândia, mesmo que sob muita pressão externa, foi sua a opção de se jogar nos braços daqueles amigos antigos num tipo de overdose de amor, morrer da falta daquilo que o mantinha vivo, morrer da abstinência, mas morrer feliz, é o que me resta imaginar.

Após sua morte o assunto foi devidamente encerrado com uma longa e "comovente" matéria no programa dominical de maior audiência e em rede nacional ${ }^{11}$, com a leitura de uma carta assinada pelos "Amigos do Sarda", e uma hashtag ${ }^{12}$ lançada \# somos todos da mesma turma. Nós, os amigos maconheiros, por tabela "da outra turma", não fomos informados do teor dessa carta e de fato tínhamos preferido não falar com jornalistas, porque queríamos estar com ele antes. E porque a dimensão de sua importância são frestas, eu intuía que faltavam ainda algumas por abrir.

11 Disponível em: http://g1.globo.com/fantastico/noticia/2017/06/conheca-historia-de-sarda-resgatadoporamigos-da-cracolandia-de-sp.html (último acesso em16/05/2019).

${ }^{12}$ Hashtags (marcadores) são ferramentas de indexação através das quais os conteúdos marcados são agrupados tornando-se facilmente pesquisáveis no ambiente online. 
Com este tema no coração e na mente, mobilizada pela perda do meu amigo, pela perda da possibilidade de escrevermos juntos como em "mais um trabalho de escola", decidi aplicar para o Mestrado em Estudos de Linguagem e iniciei minha pesquisa, meu processo de escrita solitária. Eu precisava entender o trajeto daquela história, os descaminhos impossíveis de se prever, mas, depois de trilhados, possíveis de se mapear. Era importante resgatar os sentidos perdidos daquelas palavras, lembrar do recado dado, tocar no tema-tabu - o tratamento dispensado aos dependentes químicos - tema este que retorna no exato momento em que escrevo este relato, com o sancionamento da lei $13.840^{13}$, que autoriza a internação compulsória de dependentes químicos em situação de rua, sem necessidade de autorização judicial.

\section{7) Minha pesquisa}

Já fazia quase um ano destes acontecimentos, quando, no conforto máximo de uma biblioteca climatizada, digitei apenas uma palavra na caixa de busca num banco de teses acadêmicas: "Cracolândia". Buscar. A resposta, na velocidade da luz: "Mil Fitas na Cracolândia: Amanhã é Domingo e a Craco Resiste, dissertação apresentada ao Programa de Pós-Graduação Cultura e Identidades Brasileiras do Instituto de Estudos Brasileiros da Universidade de São Paulo, para a obtenção do título de Mestra em Filosofia"14. Taquicardia. Estava tudo ali, eu havia encontrado a motivação daquele vídeo.

$\mathrm{Na}$ dissertação de Roberta Costa, ela muito mais sua biógrafa do que eu, nosso amigo em comum ficou com o subcapítulo 7.2, o último fragmento antes de suas considerações finais. Ela o intitulou "Cadu, um Profeta do Caos", e o índice nos remete à página 251. Após uma ilustração sobre a Filosofia da Redução de Riscos Danos e de um poema apócrifo, ao primeiro parágrafo de texto corrido os fatos que relata dão a este personagem mais dimensões de sua importância, frestas muito mais amplas:

Conhecia (o Alemão) desde janeiro de 2012 e suas ideias sempre me ensinaram muito sobre a Cracolândia, as drogas e a vida. Ele teve um

\footnotetext{
${ }^{13}$ Esta é a nova Lei sobre drogas sancionada pelo Presidente Jair Bolsonaro e publicada no Diário Oficial da União em 06/06/2019. A versão sancionada pelo presidente apresenta uma série de vetos em relação ao texto anteriormente aprovado pelo congresso. Disponível em: http://www.planalto.gov.br/ccivil_03/_ato2019-2022/2019/lei/L13840.htm (último acesso em21/08/2019) ${ }^{14}$ Disponível em: https://sucupira.capes.gov.br/sucupira/public/consultas/coleta/trabalhoConclusao/viewTrabalhoConclusao .jsf?popup=true\&id trabalho=5295446 (último acesso em 24/04/2019).
} 
papel fundamental na resistência à Operação Sufoco $^{15}$, pois conseguiu, junto à defensoria pública, um habeas corpus preventivo ${ }^{16}$ para ir, vir e permanecer - o que foi importante para que xs usuárixs voltassem a se reunir na Craco sem que carros, motos e bombas fossem atirados contra elxs para dispersá-los (COSTA, 2017 p. 252).

Sou, assim, catapultada à cena da gravação daquele depoimento, e reencontro meu amigo neste texto que se mostra como mais um extenso campo a ser pesquisado. Meu "objeto de pesquisa" se expandia, havia um clarão, e tudo fazia sentido.

Naquela noite da gravação, eu descobria, ele colaborava com uma amiga em sua pesquisa de mestrado, registrando em vídeo um depoimento a ela, que há cerca de cinco anos cumpria sua escrita etnográfica naquele lugar, um reduto de usuários problemáticos de drogas expostos à violência do Estado. Naquelas noites de janeiro, o coletivo A Craco Resiste, do qual a autora da dissertação participa como redutora de danos, realizava vigílias artísticas e culturais, com oficinas de escrita e rodas de conversa, como forma de proteção contra a violência policial. A ideia da série era "[mostrar] como as pessoas da Craco são bem diferentes do que o estereótipo que a grande imprensa passa, ou mesmo do que as declarações do prefeito querem fazer entender - "em campanha ele havia chamado todxs ali de lixo vivo" (COSTA, 2017, p.256).

E lá estava eu, à página 259, no tal recado em áudio onde ele também menciona um outro amigo, enchendo a boca de orgulho para dizer, "nosso diplomata", esticando o primeiro "a" e abrindo bem a boca - diplomaaata! Este amigo, que é também antropólogo e escritor, planejava uma ida a São Paulo para tentar falar com Jesus. Antropólogo e diplomata, que qualificações mais interessantes para atuar naquela fronteira, naquele contexto. Mas não deu tempo.

Ainda na biblioteca, abri novamente a caixa de diálogo de mensagens instantâneas com A Craco Resiste. E mandei um recado para Roberta. A caminho de casa, trocamos mensagens emocionadas pelo aplicativo:

“Nossa! (É a Roberta respondendo, o Dani falou pra eu vir ver sua msg... Mana, fiquei emocionada com sua msg! To aqui com os olhos cheios de água lembrando do Cadu e

\footnotetext{
${ }^{15}$ A Operação Cracolândia (também conhecida como Operação Sufoco) foi uma operação policial e política levada a cabo por autoridades das esferas estadual e municipal na cidade de São Paulo na região da Cracolândia, nas proximidades da rua Helvétia. Iniciada no dia 3 de janeiro de 2012, a operação, também conhecida como "Operação Dor e Sofrimento", cujo objetivo era combater o tráfico e expulsar viciados em crack, foi caracterizada por repressão policial aos usuários de drogas. Fonte Wikipédia (último acesso em 02/05/2019).

${ }^{16}$ Aqui, a íntegra: http://www.sasp.org.br/convenios/277-dor-sofrimento-e-liberdade-na-cracolandia.html (último acesso em 24/04/2019).
} 
daquilo q é inenarrável, mas ter escrito possibilita lembrar... Ter escrito esse mestrado fez sentido como nunca depois da sua msg! Eu q te agradeco! Fiquei feliz demais em saber q tinha vc fazendo o debate da RD ai do RJ, já é bem melhor do q nem ter sido pensado sob essa perspectiva! E nao se ache uma redutora de araque, a gente se sente assim quando o final é diferente do q gostaríamos, sentir essa impotencia é mega normal, mas é importante acolher nossos limites e possibilidades em cada momento, assim como entendemos e respeitamos os limites e possibilidades do Cadu... enfim, podemos trocar mais ideias vou te adicionar no face, mais uma vez obrigada!"

Pragmática, Roberta não perde de vista que a morte de Cadu foi uma consequência direta daquela gravação. E assim, corajosamente, ela nomeia o capítulo 7 de sua dissertação de "Consequências da Atuação da Craco Resiste" e afirma:

Se este vídeo não tivesse sido feito talvez o Cadu estivesse até hoje analisando tudo e todos de forma crítica, rindo e chorando, fazendo uso de drogas e paçoca, contribuindo com a resistência e nossos aprendizados sobre a vida (COSTA, 2017, p. 261).

Para Roberta, a explicação para tanta mobilização e repercussão no caso do Alemão/Sarda/Cadu/Jesus vem do fato de ser ele um corpo diferente que reverbera (COSTA, 2017). As vigílias culturais da Craco Resiste tinham esta proposta - lançar luz sobre a existência de corpos diferentes na Cracolândia, mas, ela admite, não havia como prever qual seria o impacto concreto desta presença. Esta noção de descaminho é uma constante em sua escrita, e palavra presente no recado que recebi de meu amigo. Vida é descaminho.

Assim, sua narrativa nos deixa essa pergunta, se o mesmo teria ocorrido se vindo de um corpo negro e oriundo da camada popular, que é o estereótipo que se espera de um usuário de crack. "Tamanha comoção talvez esteja relacionada com um lugar social esperado e naturalizado para determinadas pessoas que estão historicamente às margens, elemento considerado racismo por integrantes do movimento social" (COSTA, 2017, p.262).

A dimensão da importância de Cadu são frestas e após "encerrado o assunto" penso no vácuo deixado pelo Alemão naquele território que ele defendeu nos dez anos ali vividos. Sobre este espaço oco deixado por ele não se falou. Sobre esta dor não se escreveu. Sigo percorrendo os olhos nas páginas de Roberta e é no texto acadêmico de minha colega que encontro o projeto de vida do meu amigo, eclipsado por leituras rasas de uma realidade complexa. É quando a câmera é desligada que o mais importante vem à tona: 
[a filmagem parou aqui, mas o gravador continuou mais um pouco e transcrevo pelo seu caráter que se provou posteriormente profético] (...) Vamos ver se ajuda alguma coisa. Mas o importante é ter os 300 habeas corpus preventivos (...) Coitada da minha mãe, vai ter até o Fantástico na porta da casa dela lá no Rio. (COSTA, 2017, p. 257, grifo meu)

Profeta, megalômano certamente, acertou em cheio o desfecho midiático do que se iniciava quando aquela câmera foi ligada. Morreu "causando", morreu chamando toda a atenção que pôde, teve seu grand finale épico, do qual eu o imagino perfeitamente rindo e tirando muito sarro.

Quanto a mim, eu pego daqui; eu me lanço na espiral dos acontecimentos, tento laçar esta história voltando ao seu discurso e retomando o teor de seu recado, para garantir, mais uma vez, que tenha sido dado, em nome dos que lá ficaram. Assim meu amigo termina sua fala no vídeo gravado por Roberta:

"A minha vontade de chorar não é de raiva de você não, é de tristeza da possibilidade de ter uma pessoa tão limitada, tão limitada com relação a compreender o outro, né, com um poder tão grande, que é o de ser prefeito de São Paulo. O senhor tem um poder muito grande na sua mão. Quanto maior seu poder maior a sua responsabilidade, consigo e com os outros. Então eu peço a sua ajuda pra nós podermos conseguir... não uma saída, um caminho digno. Esteticamente também, eu gostaria de poder andar mais bonito, tá? Mas existem coisas mais importantes antes disso, tá?

Carlos Eduardo de Albuquerque Maranhão (1971-2017) foi uma forte voz na resistência à violência policial na Cracolândia (SP) desde a Operação Sufoco, em 2012, até os ataques em 2017. Nasceu no Rio de Janeiro, estudou música desde a infância e iniciou dois cursos de graduação: Direito e Geografia. Morreu chamando toda a atenção possível, com seu nome entre aspas resultando (hoje) em 16.500 ocorrências no Google. Deixou uma filha, nascida de sua união com a artista plástica Judite Pimentel.

\section{Referências}

COSTA, Roberta Marcondes. Mil Fitas na Cracolândia: Amanhã é Domingo e a Craco Resiste. São Paulo, 286 f. Dissertação de Mestrado (Programa de Pós-Graduação Culturas e Identidades Brasileiras, Instituto de Estudos Brasileiros) Universidade de São Paulo, 2017.

\section{IT IS ALWAYS GOOD TO BE RECOGNIZED ONCE MORE}

\section{Abstract}


A chemically dependent man in a state of homelessness and a leader São Paulo's so called "Crackland" makes a statement to the mayor of São Paulo on social media. After his statement goes viral, he is recognized by former colleagues, such as the writer of this paper. In this account, I try to capture his identity and the meanings that he constructs in his speech. Thus, I re-engage in my interaction with my friend in a mosaic that includes fragments of his speech, shards of my memory and re-search findings, mapping narrative routes in the online environment and beyond.

\section{Keywords}

Crackland. Autoethnography. Harm Reduction. Social Media 